\title{
Escola "sem" Partido: Enfrentamentos e Desafios para a Formação em Psicologia
}

\author{
School "Without" Party: Confrontations and Challenges for Education in Psychology \\ Escuela "sin" Partido: Enfrentamientos y Desafios para la Formación en Psicología \\ Isabel Scrivano \\ Instituto Federal de Educação, Ciência e Tecnologia do Rio de Janeiro, Rio de Janeiro, RJ, Brasil \\ E-mail: scrivano.isabel@gmail.com
}

Pedro Paulo Gastalho de Bicalho

Universidade Federal do Rio de Janeiro, Rio de Janeiro, RJ, Brasil

E-mail: ppbicalho@ufrj.br

\section{Resumo}

O presente artigo, organizado na forma de um ensaio, discorre sobre as racionalidades presentes no projeto Escola "sem" Partido. Compreende-se a política como um campo de forças, a partir da qual certas verdades acerca do governo da sociedade emergem como hegemônicas, sendo objetivadas por aparelhos disciplinares e práticas de normalização, especialmente em relação à produção de uma escola produtora de normalidade, docilidade e disciplina. Percebe-se que a escola, por meio de seus modos de educar, higienizar, ordenar e regular, foi (e é) útil para fazer funcionar determinados modos de governar. Frente a esse contexto, busca-se fazer pensar que lógicas são essas que, presentes no contemporâneo político brasileiro, propõem modos de organização do espaço escolar que sustentem, preservem e mantenham determinadas lógicas. E, por fim, analisam-se os desafios produzidos na formação de psicólogas e psicólogos, profissionais historicamente convocados a atuar no espaço escolar, e capazes de promover assujeitamentos ou enfrentamentos à proposta de assepsia política na formação de brasileiras e brasileiros no país.

Palavras-chave: processos políticos, ajustamento escolar, poder, ensino da Psicologia.

\section{Abstract}

This article, organized in the form of an essay, discusses about the rationalities present in the project School "without" Political Party. Politics is understood as a field of forces, from which certain truths about the government of society emerge as hegemonic, being objectified by disciplinary apparatus and practices of normalization, especially in relation to the production of a school producing normality, docility and discipline. It is perceived that school, through its ways of educating, sanitizing, ordering, and regulating, was (and is) useful for achieving certain modes of governing. In this context, it is relevant to think what are these modes and logics that are present in contemporary Brazilian politics, and that propose ways of organizing school space that sustain, preserve and maintain certain logics. Finally, we analyze the challenges of educating psychologists, professionals who are historically called up to work in the school and, thus, who are capable of promoting subjugations or confrontations to the proposal of political asepsis in the education of Brazilian men and women in the country.

Keywords: political processes, school adjustment, power, Psychology education. 


\section{Resumen}

Este artículo, organizado en la forma de un ensayo, aborda las racionalidades presentes en el proyecto Escuela "sin" Partido. Se comprende la política como un campo de fuerzas a partir del cual ciertas verdades sobre el gobierno de la sociedad emergen como hegemónicas, siendo objetivadas por aparatos disciplinarios y prácticas de normalización, especialmente con relación a la producción de una escuela que genere normalidad, docilidad y disciplina. Es posible percibir que la escuela, a través de sus modos de educar, higienizar, ordenar y regular, fue (y es) útil para hacer funcionar determinados modos de gobernar. Frente a ese contexto, se trata de generar un pensar sobre qué lógicas son esas que, presentes en el contemporáneo político brasileño, proponen modos de organización del espacio escolar que sostengan, preserven y mantengan determinadas lógicas. Y por fin, se analizan los desafíos producidos en la formación de psicólogos y psicólogas, profesionales históricamente convocados a actuar en el espacio escolar y de esa manera promover sometimientos o enfrentamientos a la propuesta de asepsia política en la formación de brasileños y brasileñas en el país.

Palabras claves: procesos políticos, ajuste escolar, poder, enseñanza de Psicología.

No ano de 2016, em meio a miríades de acontecimentos que reduziram a discussão política brasileira a polarizações (direita x esquerda, bem $\mathrm{x}$ mal, conservadores $\mathrm{x}$ progressistas) e que culminou com o impeachment da presidente democraticamente eleita, Dilma Rousseff, o movimento Escola "sem" Partido (ESP) ganhou muita visibilidade, principalmente depois que o primeiro projeto foi aprovado e homologado como lei em Alagoas, ${ }^{1}$ e no mesmo mês o então ministro da Educação, Mendonça Filho, recebeu o ator Alexandre Frota e representantes do movimento "Revoltados On Line" para tratar do assunto.

O movimento ESP possui uma página no Facebook e duas páginas na internet. Em uma página <http://www.escolasempartido.org>, disponibiliza espaço para que alunos e pais possam relatar práticas de professores que exercem a denominada "doutrinação político-ideológica" em sala de aula; além disso, "ensina" como identificar se o professor é ou não doutrinador, orientando as famílias que se sentem lesadas, pela chamada prática de doutrinação, a processar judicialmente professores e/ou escolas por danos materiais e morais sofridos, entre outras orientações. Em outra página <http://www.programaescolasempartido. org/>, disponibiliza o modelo do projeto de lei Escola sem Partido (Municipal, Estadual e Federal), que prevê a afixação em sala de aula de um cartaz contendo deveres do professor para que o "aluno saiba que tem o direito de não ser doutrinado por seus professores"; também lista nomes de políticos que assinaram um termo de compromisso público nas eleições de 2016, comprometendo-se "a apresentar ou apoiar projetos de lei contra a doutrinação e a propaganda política e partidária nas escolas, nos moldes do anteprojeto de lei elaborado pelo Movimento Escola sem Partido".

Nesse ano em que as discussões acerca do movimento tomaram vulto, mesmo em estados onde o referido projeto não foi aprovado como lei, muitos professores começaram a ser denunciados, processados administrativamente e afastados de suas funções. Em resposta a essa ofensiva, que visa implantar uma política de controle, denuncismo e medo nos estabelecimentos escolares, em julho de 2016 vários setores da sociedade como sindicatos, associações, partidos políticos, entidades estudantis - entendendo que iniciativas isoladas não seriam suficientes para resistir a esse projeto, reuniram-se e criaram a "Frente Nacional Contra o Projeto Escola sem Partido", denominada "Escola sem Mordaça".

O ESP também começou o receber críticas e manifestações judiciais contrárias aos projetos de lei que instituem o programa ESP nos estados da Federação, o que, pela via legal/ constitucional, coloca em xeque o movimento.

1 No estado de Alagoas o projeto recebeu o nome de Lei da Escola Livre mas obedece aos mesmos princípios da Escola sem Partido e foi promulgado como lei no dia 09/05/2016. 
A Confederação Nacional dos Trabalhadores em Estabelecimentos de Ensino (CONTEE) ajuizou, no Supremo Tribunal Federal (STF), Ação Direta de Inconstitucionalidade (ADI) contra a Lei da Escola Livre, promulgada pela Assembleia Legislativa de Alagoas, que inclusive já recebeu parecer de inconstitucionalidade do ministro Luís Roberto Barroso e segue aguardando a discussão do plenário². Além disso, a Procuradora Federal de Direitos do Cidadão, Débora Duprat, e o então Procurador Geral da República, Rodrigo Janot, já emitiram nota técnica e parecer contrários. E, seguindo a onda de contestação ao projeto, em abril de 2017 a Organização das Nações Unidas (ONU), através dos relatores da organização para a Liberdade de Expressão, de Educação e de Liberdade Religiosa, enviou um documento ao governo do presidente Michel Temer pedindo explicações sobre o mesmo.

Os administradores da página do ESP no Facebook, indignados com o questionamento, lançaram então o meme $e^{3}$ disposto a seguir para criticar a postura da ONU e colocá-la no rol de seus "inimigos".

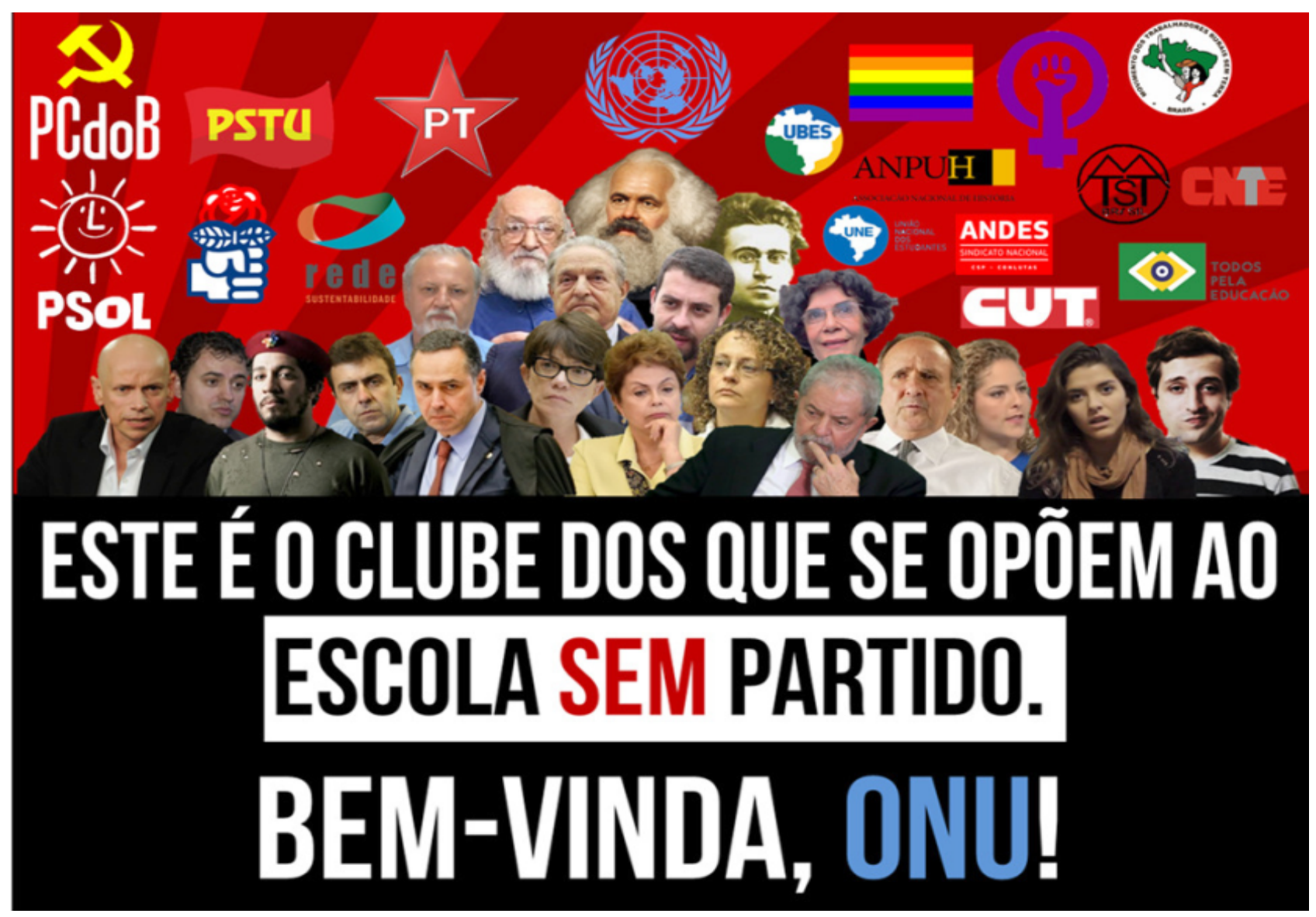

Figura 1."Clube" dos que se opõem ao ESP

Fonte: <https://www.facebook.com/escolasempartidooficial/photos

/a.346888065462191.1073741829.336441753173489/823789214438738/?type=3\&theater

2 Em novembro de 2017, data de finalização deste manuscrito.

3 Meme é um termo utilizado na internet para referir-se a um vídeo, imagem, frase ou charge que resume uma informação para que esta seja de fácil entendimento. Os memes têm a intenção de fazer "viralizar" uma informação, ou seja, alcançar muita popularidade rapidamente. 
Pensando ao contrário, ou seja, em quais seriam os integrantes do "clube" que apoia o ESP, não fica difícil perceber o vínculo ideológico do movimento com o ultraconservadorismo. Entre os principais apoiadores encontramos movimentos fundamentalistas religiosos, liberais e conservadores, como pastores evangélicos, líderes do movimento carismático católico, políticos filiados a partidos como o PR (Partido da República) ${ }^{4}$, o PSC (Partido Social Cristão) ${ }^{5}$ e o Movimento Brasil Livre (MBL) ${ }^{6}$, entre outros.

\section{A pauta neoliberal e a orientação ultraliberal do Brasil contemporâneo}

Segundo pesquisa coordenada por Esther Solano, Pablo Ortellato e Lucia Nader, realizada em São Paulo durante os protestos verde e amarelos ${ }^{7}$ liderados por movimentos como o MBL e o "Vem pra Rua", existe "um grande desacordo entre o que pensam os manifestantes e o que pensam algumas das lideranças dos protestos, que tem uma orientação ultraliberal".

Entre os manifestantes, 97\% concordam total ou parcialmente que os serviços públicos de saúde devem ser universais e $96 \%$ que devem ser gratuitos. Já $98 \%$ concordam total ou parcialmente com a universalidade da educação pública e $97 \%$ com a sua gratuidade. Até mesmo uma demanda social recente e algo heterodoxa como a gratuidade do transporte coletivo (a "tarifa zero") encontra 49\% de apoio total ou parcial entre os manifestantes. ${ }^{8}$

Os dados apontam que a pauta neoliberal de reformas e a introdução do Estado mínimo não

4 Segundo seu próprio site "O Partido da República (PR) é a legenda brasileira criada para defender as ideias do liberalismo social, doutrina formulada pelo saudoso deputado Álvaro Valle (PL-RJ), falecido no ano 2000". Fundado em 26 de outubro de 2006, o PR resulta da fusão que uniu a força do PL (Partido Liberal) ao alcance do PRONA (Partido da Reedificação da Ordem Nacional). Desde então, o Partido da República reúne, numa única legenda, o idealismo doutrinário do professor Álvaro Valle à percepção estratégico-nacionalista defendida pelo deputado e ex-presidenciável Enéas, falecido em 2007. Entre os grupos sociais identificados com o PR, destacam-se os liberais, republicanos e nacionalistas (...)". Ver: <http:// www.partidodarepublica.org.br/partido/historia_do_pr.html>.

5 Não foi possível acessar o histórico do PSC em seu próprio site (<http://www.psc.org.br/historia/〉) pois essa aba encontrava-se em construção na data de acesso (06 de out de 2017). Segundo o site <https://www.estudopratico.com. br/conheca-a-historia-do-partido-social-cristao-psc/>, "O Partido Social Cristão (PSC) foi criado em julho de 1985, mas possui uma história que começa desde 1970, com a criação do Partido Democrático Republicano. Em 1989, o PSC se aliou ao Partido Social Trabalhista (PST), Partido Trabalhista Renovador (PTR), Partido da Reconstrução Nacional (PRN). Essa coligação foi denominada como "Brasil Novo" e conseguiu levar a vitória de Fernando Collor. [...] O partido usa o termo "Social Cristão" porque acredita que o cristianismo é algo que se estende à religião; é também um estado de espírito que não exclui ninguém e que serve uma base para que as pessoas consigam tomar decisões de maneira racional. Por isso, usa termos como "pró-vida" e "pró-família". [...] Em 2013, o partido constituiu-se como oposição de direita ao Governo Dilma, quando o Partido dos Trabalhadores (PT) se posicionou favorável às pautas progressistas que o PSC se opõe. O partido faz abertamente críticas aos posicionamentos Marxistas e é historicamente conhecida por ser contra o comunismo."

6 Não foi possível encontrar o histórico do MBL em seu próprio site. Ao procurar pelo histórico do movimento em seu Facebook (<https://www.facebook.com/mblivre/posts/311257985665018〉) o máximo que encontramos foi uma reportagem da Revista Exame intitulada "A 'startup' que surgiu para fazer protestos" (<https://exame.abril.com.br/ brasil/noticias/conheca-o-mbl-a-startup-que-surgiu-para-fazer-protestos $>$ ). Segundo tal reportagem, "a equipe do MBL se define como liberal em relação à economia e prega o ideal do Estado mínimo em todos os sentidos possíveis" e "o negócio do paulista Kim Kataguiri, de 19 anos, e de outros três jovens é, no entanto, convencer pessoas de que a estadia de Dilma Rousseffno Palácio do Planalto deve ser reduzida".

7 Os autores da pesquisa nomeiam de verde-e-amarelos os manifestantes que estiveram nas ruas apoiando o impeachment da presidente Dilma Rousseff.

8 Link para dados da pesquisa: 〈http://gpopai.usp.br/pesquisa/160815/> 
são bem aceitas nem mesmo pelo brasileiro que se manifestou a favor do impeachment; mas, por outro lado, 32,6\% dos pesquisados se declararam "muito conservadores", e 36,6\% "um pouco conservadores".

Transversalizando esses dados com o movimento ESP, percebe-se que o movimento utiliza a estratégia de não divulgar suas alianças com institutos liberais, mas faz questão de alardear parcerias com partidos, parlamentares e grupos conservadores para conseguir adeptos. Para ilustrar tal fato, trataremos nesse manuscrito das estratégias utilizadas pelo movimento nos trabalhos da Comissão Escola sem Partido instalada na Câmara dos Deputados em Brasília.

A elaboração de leis (além de outras atribuições, como a fiscalização dos atos do Poder Executivo) compete ao Poder Legislativo, que no âmbito federal $^{9}$ é constituído pelo Congresso Nacional que, desde 1891, é composto por duas Casas Legislativas autônomas: a Câmara dos Deputados e o Senado Federal ${ }^{10}$ (Bicalho, 2016).

A Câmara dos Deputados é constituída pelos representantes eleitos em número proporcional ao da população de cada estado e do Distrito Federal, para um mandato de quatro anos. Na quinquagésima quinta legislatura da história política do país ${ }^{11}$ iniciada no ano de 2015 -, a Câmara passou a contar com 513 membros, sendo que estado de São Paulo tem o maior número de deputados eleitos, com setenta representantes: o número máximo por estado permitido pela Constituição. Os estados de menor população elegem o número mínimo previsto constitucionalmente: oito deputados cada um (Bicalho, 2016).

O Senado Federal, embora também composto por membros escolhidos em eleição direta pelo povo (para um mandato de oito anos), representa os interesses dos estados e do Distrito Federal como unidades da federação, independente do tamanho da respectiva população. Por isso, o número de senadores eleitos por estado e pelo Distrito Federal não é proporcional ao número de habitantes, mas fixo: três por unidade da federação, totalizando hoje 81 membros na Casa (Lemos, 2008).

Os trabalhos de elaboração de leis se desenvolvem basicamente em duas fases distintas em cada Casa Legislativa: o momento em que os projetos tramitam nas comissões ${ }^{12}$, e após o momento em que os projetos são discutidos e votados em Plenário.

9Nos estados, o Poder Legislativo é composto pelas Assembleias Legislativas e Tribunal de Contas do Estado, e, nos municípios, pelas Câmaras Municipais e Tribunal de Contas dos Municípios. Neste capítulo discutiremos apenas o Poder Legislativo Federal, embora a lógica de funcionamento seja a mesma. E, por conseguinte, a atuação de uma Psicologia Jurídica legislativa também.

10 Integra ainda, ao Poder Legislativo Federal, o Tribunal de Contas da União, órgão que auxilia o Congresso Nacional nas atividades de controle e fiscalização externa (fiscalização contábil, financeira, orçamentária, operacional e patrimonial da União e das entidades da administração pública direta e indireta, quanto à legalidade, legitimidade, economicidade, aplicação das subvenções e renúncia de receitas). Por não ser um órgão para o qual compete a elaboração de leis, neste capítulo o funcionamento de tal instituição não será mencionado.

11 Com a proclamação da República, a tradição constitucional brasileira espelhou-se no modelo norte-americano para criar um Legislativo federal bicameral, dividindo-o em duas vertentes, uma a representar os estados federados, com senadores eleitos pelo sistema majoritário, e outra o povo, com deputados eleitos pelo sistema proporcional, formando portanto duas câmaras mutuamente revisoras. Foram exceções as Constituições de 1934 e 1937, que preconizavam o unicameralismo. A doutrina republicana entende que o bicameralismo é o sistema mais apropriado às federações, ao apontar o Senado como a câmara representativa dos estados federados (Araújo, 2012).

12 A Câmara Federal possui, hoje, vinte comissões permanentes: Comissão de Agricultura, Pecuária, Abastecimento e Desenvolvimento Rural; Comissão da Amazônia, Integração Nacional e de Desenvolvimento Regional; Comissão de Ciência e Tecnologia, Comunicação e Informática; Comissão de Constituição e Justiça e de Cidadania; Comissão de Defesa do Consumidor; Comissão de Desenvolvimento Econômico, Indústria e Comércio; Comissão de Desenvolvimento Urbano; Comissão de Direitos Humanos e Minorias; Comissão de Educação e Cultura; Comissão de Finanças e Tributação; Comissão de Fiscalização Financeira e Controle; Comissão de Legislação Participativa; Comissão de Minas e Energia; Comissão de Meio Ambiente e Desenvolvimento Sustentável; Comissão de Relações Exteriores e Defesa Nacional; Comissão de Seguridade Social e Família; Comissão de Trabalho, de Administração e Serviço Público; Comissão de Viação e Transportes; Comissão de Segurança Pública e Combate ao Crime Organizado; Comissão de Turismo e Desporto. 


\section{Escola "sem" Partido?}

Em outubro de 2016, foi constituída e instalada uma Comissão Especial na Câmara Federal ${ }^{13}$ com o objetivo de proferir parecer ao projeto de lei $n^{\circ}$ 7180/2014, do deputado Erivelton Santana (PEN$\mathrm{BA})$, que visa incluir "entre os princípios do ensino o respeito às convicções do aluno, de seus pais ou responsáveis, dando precedência aos valores de ordem familiar sobre a educação escolar nos aspectos relacionados à educação moral, sexual e religiosa”, o que alteraria a $\mathrm{LDB}$, e também sobre os demais projetos de lei apensados. São cinco os projetos de lei apensados ao primeiro, entre os quais estão o PL 7181/2014 (Erivelton Santana - PEN-BA), que versa sobre o mesmo assunto do anterior, e tem o intuito de modificar os Parâmetros Curriculares Nacionais (PCNs); o PL 867/2015 (Izalci Lucas - PSDB-DF), que "inclui o "Programa Escola sem Partido" na LDB”; o PL6005/2016 (JeanWyllys - PSOL-RJ), que "institui o programa "Escola Livre" em todo o território nacional"; o PL 1859/2015 (Allan Rick - DEM-AC), que acrescenta parágrafo único ao art $3^{\circ}$ da LDB indicando que "a educação não desenvolverá políticas de ensino, nem adotará currículo escolar, disciplinas obrigatórias, ou mesmo de forma complementar ou facultativa, que tendam a aplicar a ideologia de gênero, o termo 'gênero' ou 'orientação sexual”; e o PL 5487/2016 (Professor Victório Galli - PSC-MT), que "institui a proibição de orientação e distribuição de livros às escolas públicas pelo Ministério da Educação e Cultura que verse sobre orientação de diversidade sexual para crianças e adolescentes”. É importante ressaltar que, com exceção do PL que cria o programa "Escola Livre", o qual pode ser considerado como a antítese do "Escola sem Partido", todos os outros PLs em discussão nessa Comissão Especial querem retirar do âmbito escolar qualquer tema relacionado à ordem moral, sexual e religiosa.

Vale ressaltar também que o PL que dá origem à discussão (7180/2014) não se refere ao programa ESP em momento algum, embora aborde o mesmo tema, mas é o "Escola sem Partido" que aparece como nome da Comissão Especial. É importante que isso seja ressaltado porque os "defensores" do ESP insistem em afirmar que o referido projeto quer apenas afixar um cartaz com os deveres do professor nas salas de aula do país; porém, analisando a "árvore de projetos" que está sendo apreciada no âmbito da Comissão, percebe-se que a proposta é muito mais ampla e complexa.

Chama a atenção também que os trinta deputados titulares e igual número de suplentes ${ }^{14}$ que compõem a Comissão Especial são em sua maioria membros da Frente Parlamentar Evangélica (mais conhecida como bancada da Bíblia), da Frente Parlamentar Mista Católica Apostólica Romana, da Frente Parlamentar de Segurança Pública (mais conhecida como bancada da bala), como descrito a seguir.

A Comissão Especial - destinada a proferir parecer ao Projeto de Lei $n^{\circ} 7180$, de 2014, do Sr. Erivelton Santana, e apensados é composta dos seguintes membros:

Presidente: Marcos Rogério (DEM/RO)* $1^{\circ}$ Vice-Presidente: Pastor Eurico (PHS/PE)*\# $2^{\circ}$ Vice-Presidente: Lincoln Portela (PRB/MG)*\# $3^{\circ}$ Vice-Presidente: Hildo Rocha (PMDB/MA) \# Relator: Flavinho (PSB/SP)*

13 A cada legislatura, a Câmara dos deputados constitui Comissões Parlamentares, que podem ser permanentes ou temporárias, para promover estudos, debates e audiências com a participação da sociedade. As comissões especiais são temporárias e têm a finalidade de emitir pareceres sobre temas específicos. A comissão especial em análise aqui foi constituída no dia 05 de outubro de 2016 e possui prazo de 40 (quarenta) sessões para proferir parecer, contadas a partir da data de sua constituição.

14 Documento de criação da Comissão está disponível em < http://www2.camara.leg.br/atividade-legislativa/comissoes/ comissoes-temporarias/especiais/55a-legislatura/pl-7180-14-valores-de-ordem-familiar-na-educacao/conheca-a-comissao/criacao-e-constituicao/ato-de-criacao>. 
Tabela 1

Comissão Especial PL7180/14

TITULARES $\quad$ SUPLENTES

PMDB/PP/PTB/DEM/PRB/SD/PSC/PHS/PODE/PMN/PRP/ PSDC/PEN/PRTB

\begin{tabular}{|c|c|}
\hline Alan Rick PRB/AC (Gab. 650-IV) - vaga do PR $\left(^{*}\right)(\#)$ & $\left({ }^{*}\right)(\#)$ Arnaldo Faria de Sá PTB/SP (Gab. 929-IV) \\
\hline Antonio Bulhões PRB/SP (Gab. 327-IV) $\left(^{*}\right)(\#)$ & ${ }^{(*)}$ Carlos Andrade PHS/RR (Gab. 758-IV) \\
\hline Bacelar PODE/BA (Gab. 381-III)(\#) & $\left(^{*}\right)(\#)$ Ezequiel Teixeira PODE/RJ (Gab. 210-IV) \\
\hline DarcísioPerondi PMDB/RS (Gab. 518-IV)(\#) & (“)(\#)José Carlos Aleluia DEM/BA (Gab. 854-IV) \\
\hline Delegado Francischini SD/PR (Gab. 265-III) & Junior Marreca PEN/MA (Gab. 537-IV) \\
\hline Eduardo Bolsonaro PSC/SP (Gab. 481-III) $\left(^{*}\right)(\#)\left({ }^{*}\right)$ & (\#)Mauro Pereira PMDB/RS (Gab. 843-IV) \\
\hline Hildo Rocha PMDB/MA (Gab. 734-IV)(\#) & ${ }^{(*)}$ Pr. Marco Feliciano PSC/SP (Gab. 254-IV) \\
\hline João Campos PRB/GO (Gab. 315-IV) - vaga do PPS(*)(\#) & (*)Roberto Alves PRB/SP (Gab. 946-IV) \\
\hline Josué Bengtson PTB/PA (Gab. 505-IV) $\left(^{*}\right)\left({ }^{(*)}\right.$ & (“)Soraya Santos PMDB/RJ (Gab. 352-IV) \\
\hline Lincoln Portela PRB/MG (Gab. 615-IV) $\left({ }^{*}\right)(\#)$ & \\
\hline Marcos Rogério DEM/RO (Gab. 930-IV) ${ }^{*}$ ) & 4 vaga(s) \\
\hline
\end{tabular}

Pastor Eurico PHS/PE (Gab. 906-IV)(*)(\#)

Ricardo Izar PP/SP (Gab. 634-IV) $\left.\left(^{*}\right)()^{*}\right)$

$2 \operatorname{vaga}(s)$

$\mathrm{PT} / \mathrm{PSD} / \mathrm{PR} / \mathrm{PROS} / \mathrm{PCdoB}$

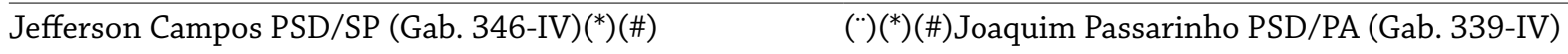

Paulo Freire PR/SP (Gab. 416-IV) $\left.\left({ }^{*}\right)(\#)()^{*}\right)$

Paulo Pimenta PT/RS (Gab. 552-IV)(\#)(")

(Deputado do DEM ocupa a vaga)

Pedro Uczai PT/SC (Gab. 229-IV)(*)(“)

7 vaga(s)

Professora Marcivania PCdoB/AP (Gab. 338-IV)

(Deputado do PRB ocupa a vaga)

3 vaga(s)

PSDB/PSB/PPS/PV

Creuza Pereira PSB/PE (Gab. 662-IV) (\#)

(")Átila Lira PSB/PI (Gab. 640-IV)

Danilo Cabral PSB/PE (Gab. 423-IV)

Fábio Sousa PSDB/GO (Gab. 271-III) $\left(^{*}\right)(\#)$

$(")\left({ }^{*}\right)(\#)$ Izalci Lucas PSDB/DF (Gab. 602-IV)

Flavinho PSB/SP (Gab. 369-III)(*)(")

Rogério Marinho PSDB/RN (Gab. 446-IV)(\#)

(Deputado do PRB ocupa a vaga)

3 vaga(s)

1 vaga(s)

PDT

Pompeo de Mattos PDT/RS (Gab. 704-IV) $\left(^{*}\right)(\#)$

1 vaga(s)

PSOL

Glauber Braga PSOL/RJ (Gab. 362-IV)

Jean Wyllys PSOL/RJ (Gab. 646-IV)

(*) Membro da Frente Parlamentar Evangélica - (mais conhecida como Bancada da Bíblia); (\#) Membro da Frente Parlamentar de Segurança Pública (mais conhecida como Bancada da Bala); (") Membro da Frente Parlamentar Mista Católica Apostólica Romana

Fonte: <http://www2.camara.leg.br/atividade-legislativa/comissoes/comissoes-temporarias/especiais/55a-legislatura/pl-7180-

-14-valores-de-ordem-familiar-na-educacao/conheca-a-comissao/membros-da-comissao>

Como afirmou o deputado Bacelar (PODE/

BA), quando presidiu o Seminário da Comissão Especial ESP em Salvador,

$\mathrm{Na}$ Comissão nós vamos perder. São 39 membros e nós só temos 8 votos. Essa Comissão foi tirada a dedo, porque além do caráter político tem o caráter religioso. O presidente da Comissão é pastor, o relator é o líder do movimento carismático da Igreja católica,... é o pastor Marco Feliciano, é o pastor [inaudível] ... É uma concentração religiosa muito grande. ${ }^{15}$

15 Seminário da Comissão Especial da Câmara Federal realizado na Câmara Municipal de Salvador no dia 29 de maio 
O fato de quase todos os deputados pertencerem a uma Frente Parlamentar de cunho religioso e/ou punitivista não implicaria em problema algum se estes não se utilizassem do espaço da Comissão para abordar pautas sociais com o intuito de instaurar pânico moral (Cohen citado por Miskolci, 2007) ou guerras psicológicas (Martin-Baró,1987), para assim fazer valer a sua visão de mundo como verdade única.

Em fevereiro de 2017, iniciaram as audiências públicas, que podem ser requisitadas pelo relator ou qualquer outro deputado que faça parte da Comissão, mediante aprovação do plenário. Segundo o Plano de Trabalho da Comissão ${ }^{16}$, visando a um "processo o mais democrático e transparente possível" e "que se possa chegar a um excelente relatório final”, essas audiências têm acontecido periodicamente nos plenários da Câmara Federal, em Brasília, e, priorizam "a colaboração de órgãos, instituições, entidades e pessoas jurídicas, públicas e privadas, e representantes da sociedade civil que tenham relação com a matéria objeto de deliberação", ou seja, o PL 7.180/2014 e seus apensados.

Mas, ao contrário de um "processo o mais democrático e transparente possível”, o que se instala é um ambiente hostil e de polarização. Os convidados que se colocam contra o ESP são invariavelmente atacados, interrompidos em suas falas e desqualificados pelo público presente, que sempre conta com maioria favorável ao ESP, e por parlamentares que advogam a favor da causa, ameaçando as liberdades constitucionalmente asseguradas.

O cenário é descrito por Daniel Cara, coordenador geral da Campanha Nacional pelo Direito à Educação, e um dos convidados a participar de audiência pública na Comissão Especial Escola sem Partido realizada no dia 07 de março de 2017.

Quando a gente vai no Congresso Nacional a situação é mais ou menos a seguinte: pelo menos foi quando eu fui e acho que com o Fernando (Penna) foi também, era eu contra o ESP, o plenário todo com militantes do ESP, todos os deputados favoráveis ao ESP e só o Bacelar, que é o deputado da Bahia, que era contrário também ao ESP e tinha três minutos de fala. ${ }^{17}$

Ao final da exposição dos convidados, os deputados podem fazer considerações finais, e quase todas manipulam um discurso moralista e de contraposição ao comunismo, ao marxismo, ao "esquerdismo", às lutas das minorias, à "ideologia de gênero"18, entre outros. Clamam por punição aos professores que se "aliam" a essas causas, e não raramente atacam parlamentares de partidos de esquerda.

É o cúmulo do absurdo o que nós estamos vivendo hoje em dia, Sr presidente. E é muito bonito, o Toni Reis veio aqui e falou (em) desenvolvimento da pessoa humana, aprender e ensinar, divulgar o saber e depois me surpreendeu, deputado Lincoln, quando falou que o PNE foi aprovado aqui através de acordo. Ora, então o que o MEC fez com os planos municipais de educação, atropelando o PNE e sugerindo que todos os planos municipais de educação contivessem a ideologia de gênero?

de 2017. Link para acesso: <https://www.youtube.com/watch?v=VzEAMolBb24>.

16 Link para acesso: <http://www2.camara.leg.br/atividade-legislativa/comissoes/comissoes-temporarias/especiais/55a-legislatura/pl-7180-14-valores-de-ordem-familiar-na-educacao/documentos/outros-documentos/plano-de-trabalho>

17 Fala realizada na mesa "Por uma Educação Democrática” realizada no dia 29 de junho de 2017 por ocasião da fundação do Movimento Educação Democrática.

18 O termo "ideologia de gênero" foi inventado por movimentos conservadores para manipular a opinião pública e fazê-la acreditar que discutir gênero na escola seria um meio de inculcar nos alunos "valores imorais" sobre sexo e a possibilidade de escolher ser menino ou menina, colocando em risco a dita "família tradicional brasileira" (Cassal, Monteiro,\& Bicalho, 2011). É importante destacar que discutir gênero em sala de aula não tem nada a ver com isso. Para maiores problematizações: Bortolini, Bicalho, Mostafa, Colbert, Polato,\& Pinheiro (2014). 
E depois a Base Nacional Comum Curricular, que o então governo Dilma Rousseff mandou para essa casa, recheado de ideologia de gênero em todas as matérias. (...) Isso não vai entrar na escola. E aqui eu abro um parêntese para fazer uma crítica ao professor Miguel Nagib e ao ESP. Estáaqui uma foto, provavelmente aqui são professores rindo, e com o seguinte dizer no cartaz: 'Sou professor e vou falar de gênero para seu filho e sua filha.' Para ser bem otimista, presidente, é falando 'dane-se' para todo mundo que está aqui, e na nossa cara. O projeto ESP tem que prever uma criminalização, uma pena, porque eles sabem o que estão fazendo. E estão fazendo de tão ruim que esses 13 anos de PT vão ser dificeis de serem recuperados. A economia a gente corre atrás. Corrupção, a gente pode debater um punhado de lei. Agora, a molecada formada na escola, nesse pensamento de Paulo Freire, isso aí vai demorar décadas. Eles estão na verdade é mudando aqui a estratégia. Passaram do Marx, tentaram tomar quartéis no passado. Não conseguiram graças aos militares. Obrigado, militares de 64! E tentam agora através de Gramsci, filósofo italiano, que prega o seguinte: 'Não tomem quartéis, tomem escolas!' E têm feito esse trabalho (Deputado Eduardo Bolsonaro - PSC-SP). ${ }^{19}$

Quantos parlamentares de esquerda ficaram aqui para debater? Onde eles estão? Por que na hora do debate inteligente, na hora do debate sério, na hora do debate com neutralidade 'pernas pra que te quero'? Essa é a postura deles (Deputado Federal Lincoln Portela PRB-MG). ${ }^{20}$
Além disso, os mesmos professores que são rotulados de doutrinadores são descritos como incapazes e com problemas em sua formação profissional e, por isso, culpabilizados pelos baixos resultados do Brasil no Programa Internacional de Avaliação de Estudantes (PISA) ${ }^{21}$ ou na Avaliação Nacional da Alfabetização (ANA).

A ANA, Avaliação Nacional da Alfabetização, (aplicada) em 2015, em crianças na $3^{a}$ série do ensino fundamental, com 8 anos de idade, demonstrou que $56 \%$ das crianças brasileiras são analfabetas ou analfabetas funcionais. Significa então que $44 \%$ estão plenamente alfabetizadas? Não. Apenas 11\%. As demais encontram-se no estágio intermediário. Isso é fruto justamente da doutrinação na formação dos professores alfabetizadores, que são formados nas nossas universidades com uma grade curricular sem evidência científica e com viés ideológico doutrinário de esquerda. O professor sai da faculdade sabendo quem é Marx, quem é Engels, quem é Paulo Freire, quem é Emília Ferrero, mas não conhece metodologia educacional para educar a criança na idade certa. No mundo inteiro se discute metodologia de alfabetização. No Brasil, se você falar aqui de fônico ou silábico vocêe alcunhado de fascista, de liberal, que quer ressuscitar a decoreba. "Vovô viu a uva" numa cartilha. Eu aprendi numa tabuada. Hoje as crianças são submetidas a um pseudo-método de alfabetização, que é o construtivismo. Que não educa, deseduca. E além de deseducar confunde a cabeça das crianças. E o que é pior, impede que os professores tenham uma

19 Considerações proferidas na Audiência Pública da Comissão Especial do ESP na Câmara Federal, no dia 07/02/2017 às 17:52:55. Disponível em: <http://www2.camara.leg.br/atividade-legislativa/comissoes/comissoes-temporarias/ especiais/55a-legislatura/pl-7180-14-valores-de-ordem-familiar-na-educacao/reunioes/pesquisa/videoArquivo?codSessao $=58780 \&$ codReuniao $=45974$ videoTitulo $>$

20 Considerações proferidas na Audiência Pública da Comissão Especial do ESP na Câmara Federal, no dia 07/02/2017 às 17:56:58. Disponível em: <http://www2.camara.leg.br/atividade-legislativa/comissoes/comissoes-temporarias/ especiais/55a-legislatura/pl-7180-14-valores-de-ordem-familiar-na-educacao/reunioes/pesquisa/videoArquivo?codSessao $=58780 \& \operatorname{codReuniao}=45974 \#$ videoTitulo $>$

21 Em inglês, "Programme for InternationalStudent Assessment". 
condição de aplicar uma metodologia adequada. E está aí o resultado. A doutrinação nas escolas está causando uma tragédia na escola pública brasileira. As pessoas que tem condição de colocar seus filhos na escola privada tentam se proteger como se fossem oásis ou ilhas. Mas nem elas estão protegidas porque quem forma o professor são as universidades como um todo. Então todos estão submetidos a um mesmo processo depredador da qualidade da educação brasileira. (Deputado Federal Rogério Marinho - PSDB-RN). ${ }^{22}$

O expositor Toni Reis falou que a Educação brasileira tem como patrono Paulo Freire. Ele está certo. Na Educação brasileira o patrono é Paulo Freire. Ficam nesse devaneio de senso crítico e não se importam com aquilo que estamos debatendo aqui que é exatamente o professor passar o seu conhecimento para o aluno. Prova disso é o exame do PISA do ano passado. Dentre 70 países, presidente, o Brasil assumiu as seguintes posições: $59^{\circ}$ na leitura e $66^{\circ}$ em matemática. Fica até difícil de saber à frente de quem nós estamos. Será que são as grandes potências? Coreia do Sul? Singapura? Estados Unidos? Óbvio que não! Então, na prática, o que nós temos é: Sim, há uma doutrinação nas escolas! (Deputado Federal Eduardo Bolsonaro - PSC-SP $)^{23}$

Esses discursos inflamados dos parlamentares são postados em suas respectivas páginas nas redes sociais e replicados em muitas outras páginas do Facebook e também do Youtube, como, por exemplo, nas páginas do MBL, da Caneta Desesquerdizadora ${ }^{24}$ ou dos Revoltados ON LINE. Nessas páginas, é possível encontrar vídeos com os seguintes títulos:

"Eduardo BOLSONARO DESTRÓI ESQUERDISTA Em Comissão da ESCOLA SEM PARTIDO"(https://www.youtube.com/ watch?v=fuUmVEvVSLc); "Eduardo Bolsonaro e Feliciano fazem 'presidenta' da UNE passar vergonha durante debate" (https://www.youtube. $\mathrm{com} /$ watch? $\mathrm{v}=\mathrm{m} 6 \mathrm{wObTz7ukA}$ ); "Eduardo Bolsonaro desbanca líder LGBT,adorador de Paulo Freire" (https://www.youtube.com/ watch?v=uRVkrtGOxEQ); DETONOU! Marco Feliciano DESTRÓI Esquerdistas na Comissão do Escola Sem Partido"(https://www.youtube.com/ watch?v=YF3zrKSJHOU); "Marinho dá uma AULA aos Marxistas no Escola sem Partido" (https:// www.youtube.com/watch?v=FCAs7hTvkVE); "Professor perseguido dá o troco na ESQUERDA" < ht t p s:// www.you tube.com/ watch?v=QtJxE9gKz7Y>; "'Ex Lobotomizado', Destrói Críticos do Projeto Escola Sem Partido na Câmara" (https://www.youtube.com/ watch?v=pxCnrSHWRNM); "Eduardo Bolsonaro desmoraliza Glauber no Escola sem Partido”(https:// www.youtube.com/watch?v=HEbQcGeqFkA).

Os títulos dados aos vídeos dos parlamentares manifestam discursos de ódio às pessoas que adotam uma postura contrária ao ESP. E o movimento se aproveita da polarização política,

22 Considerações proferidas na Audiência Pública da Comissão Especial do ESP na Câmara Federal, no dia 07/02/2017 às 17:28:38. Disponível em: <http://www2.camara.leg.br/atividade-legislativa/comissoes/comissoes-temporarias/ especiais/55a-legislatura/pl-7180-14-valores-de-ordem-familiar-na-educacao/reunioes/pesquisa/videoArquivo?codSessao $=58780 \& \operatorname{codReuniao}=45974 \#$ videoTitulo $>$

23 Considerações proferidas na Audiência Pública da Comissão Especial do ESP na Câmara Federal, no dia 07/02/2017 às 17:52:55. Disponível em: <http://www2.camara.leg.br/atividade-legislativa/comissoes/comissoes-temporarias/ especiais/55a-legislatura/pl-7180-14-valores-de-ordem-familiar-na-educacao/reunioes/pesquisa/videoArquivo?codSessao $=58780 \&$ codReuniao $=45974 \#$ videoTitulo $>$

24 Pedro Paulo Bicalho, um dos autores deste artigo, já teve perfil criado pela "Caneta Desesquerdizadora”, porépoca de manifestação pública contra a decisão liminar de juiz do Tribunal Regional Federal da $1^{\text {a. }}$ Região, acerca do projeto de reorientação sexual que visa descaracterizar a resolução 01/1999 do Conselho Federal de Psicologia (decisão popularmente conhecida por "projeto da cura gay"). Em apenas quatro horas após a postagem, já havia mais de duas mil curtidas, quinhentos compartilhamentos e duzentos comentários na rede, em sua grande maioria contendo discursos de ódio. 
que se instaurou no Brasil nos últimos anos, para construir o perfil de um novo inimigo político: o dito professor doutrinador. Sendo assim, o ESP se utiliza do discurso de que crianças e adolescentes não têm como escapar da doutrinação imposta por professores por serem audiência cativa, e de que esses mesmos professores estariam usurpando das famílias o direito de dar educação moral aos filhos de acordo com suas próprias convicções, para instaurar o medo como operador político. "Está instaurada assim, a sociedade com base na produção do medo, pois é através deste sentimento que passamos a ver o mundo e a nos situar nele" (Moreira, Fulton, Uziel \& Bicalho, 2010, p. 300).

Senhor presidente, Senhor relator, quando tiver um projeto como esse eu acho que nós temos que ter primeiro uma decisão, um posicionamento nesse Brasil. De quem é a responsabilidade principal na educação dos nossos filhos? É da família ou é da escola? Onde é que se forma o caráter das crianças, dos nossos filhos... é dentro da família ou na escola? Eu acho que é na família. Eu acho que a escola, ela é um complemento. Ela complementa, ela ajuda, ela complementa a educação. Então, (...) nós temos que pensar que a escola não pode se contrapor à família. Ela não pode se contrapor a pensamentos que a família traz" (Deputado Federal Joaquim Passarinho - PSD-PA). ${ }^{25}$

Zaffaroni (2011) descreve o autoritarismo cool do século XXI como "uma guerra sem inimigo definido; o único inimigo que invariavelmente reconhece é o mesmo de todo autoritarismo: quem confronta seu discurso" (p.78). Relata que esse tipo de autoritarismo foi desenvolvido nos Estados Unidos após o final da Guerra Fria e do advento da globalização, e mostra que esse discurso ideologicamente conservador e controlador se espalhou de maneira diferenciada na América Latina, onde "a polarização de riqueza acentuada pela economia globalizada deteriorou gravemente as classes médias, tornando-as anômicas"(p.72). Segundo ele,

(...) a anomia avança no sentido originário de Durkheim e o discurso popularesco, grosseiro e primitivo tem maior aceitação porque parece compensar a segurança perdida por causa da globalização: a sociedade perde coesão e está ávida por um discurso que lhe devolva essa perspectiva, por primitivo, vingativo e volkisch que seja: a coesão é alcançada através de um discurso simplista que clama pela vingança pura e simples. Dado que a mensagem é facilmente propagada, rentável para os empresários da comunicação social, funcional para o controle dos excluídos, bem sucedida entre eles e satisfatória para as classes médias degradadas, não é raro que políticos se apoderem desse discurso e até o disputem. (...) Assim se impõe o discurso único do novo autoritarismo (p. 72-73).

Um dos argumentos mais utilizados pelo ESP para mobilizar o medo nas famílias, provocar pânico moral (Cohen citado por Miskolci, 2007) ou guerras psicológicas (Martin-Baró,1987) e conseguir adesão da população é o da implantação da ideologia de gênero nas escolas. Isso aparece em memes ${ }^{26}$ divulgados na página do ESP, como descreve Penna (2016):

Na minha opinião, a imagem mais chocante de todas é a que reproduzo abaixo, que tem relação

25 Considerações proferidas na Audiência Pública da Comissão Especial do ESP na Câmara Federal, no dia 07/02/2017 às 17:48:55. Disponível em: <http://www2.camara.leg.br/atividade-legislativa/comissoes/comissoes-temporarias/ especiais/55a-legislatura/pl-7180-14-valores-de-ordem-familiar-na-educacao/reunioes/pesquisa/videoArquivo?codSessao $=58780 \& \operatorname{codReuniao}=45974 \#$ videoTitulo $>$

26 Disponível em: <https://www.facebook.com/escolasempartidooficial/photos/

pb.336441753173489.-2207520000.1492270099./703760683108259/?type=3\&theater > 
com o termo 'ideologia de gênero'. Este termo foi criado por grupos que tentam desqualificar $e$, até mesmo, demonizar o trabalho com a questão de gênero nas salas de aula. A meta, em grande parte já alcançada, é criar um termo que remeta a medos difusos de que as crianças aprenderiam a ser gays e lésbicas em sala de aula e que os professores estariam tentando destruir a família tradicional. ${ }^{27}$

E aparece também em discursos proferidos pelos deputados da Comissão:

"Porque o que eles têmé a imposição doutrinária. O que eles têm é a doutrinação ideológica nas escolas. Homem não nasce homem. Mulher não nasce mulher. Mas gay nasce gay. Onde nós estamos? A que ponto a irracionalidade bateu no ser humano? A que ponto? (Deputado Federal Lincoln Portela - PRB-MG)."28

Segundo Cohen (citado por Miskolci, 2007), um pânico moral emerge quando:

Uma condição, um episódio, uma pessoa ou um grupo de pessoas passa a ser definido como um perigo para valores e interesses societários; sua natureza é apresentada de uma forma estilizada e estereotipada pela mídia de massa; as barricadas morais são preenchidas por editores, bispos, políticos e outras pessoas de Direita; especialistas socialmente aceitos pronunciam seus diagnósticos e soluções; recorre-se a formas de enfrentamento ou desenvolvem-nas.(...)Algumas vezes, o objeto do pânico é absolutamente novo e outras vezes é algo que existia há muito tempo, mas repentinamente ganha notoriedade. Algumas vezes o pânico passa e é esquecido,exceto no folclore e na memória coletiva. Outras vezes ele tem repercussões mais sérias e duradouras e pode produzir mudanças tais como aquelas em política legal e social ou até mesmo na forma como a sociedade se compreende (p. 111).

Segundo Martin-Baró (1987), a guerra psicológica tem como foco "quebrar a pessoa, acabar com sua autonomia e sua capacidade de oposição, não dar espaço para sua liberdade e suas opções" (p.277), e se utiliza de um método cujo principal recurso é instalar um sentimento de insegurança para influenciar as pessoas por inteiro "ganhando seus corações e suas mentes" para que se "submetam aos ditames do poder". Deve-se destacar que essa guerra psicológica, embora tenha sido utilizada há 30 anos em El Salvador por grupos diferentes e em um contexto social específico daquele país, tem muito em comum com as táticas que o ESP tem promovido contra os professores no Brasil de hoje. Ou seja, utilizando-se de categorias como neutralidade científica em sobreposição à liberdade de expressão e de pensamento, o que se quer é estabelecer o controle do trabalho de professores e técnicos da educação para que eles atuem apenas instruindo, docilizando corpos de estudantes e produzindo subjetividades serializadas, úteis somente a determinadas correntes ideológicas, religiosas e econômicas que estão a serviço do controle social.

Castro (2004) descreve o controle social como um conjunto de táticas, estratégias e forças para a construção da hegemonia, isto é, para a busca da legitimação ou garantia do consenso; ou, em caso de fracasso, para a submissão forçada dos que não se integram à ideologia dominante"(p.153).

É interessante observar que, ao mesmo tempo em que os trabalhos da Comissão Especial "Escola sem Partido" vão ganhando visibilidade e adeptos

27 Imagem original pode ser encontrada no site <https://www.facebook.com/escolasempartidooficial/photos/ pb.336441753173489.-2207520000.1492270099./703760683108259/?type=3\&theater >

28 Considerações proferidas na Audiência Pública da Comissão Especial do ESP na Câmara Federal, no dia 07/02/2017 às 17:56:58. Disponível em: <http://www2.camara.leg.br/atividade-legislativa/comissoes/comissoes-temporarias/ especiais/55a-legislatura/pl-7180-14-valores-de-ordem-familiar-na-educacao/reunioes/pesquisa/videoArquivo?codSessao $=58780 \& \operatorname{codReuniao}=45974 \#$ videoTitulo $>$ 


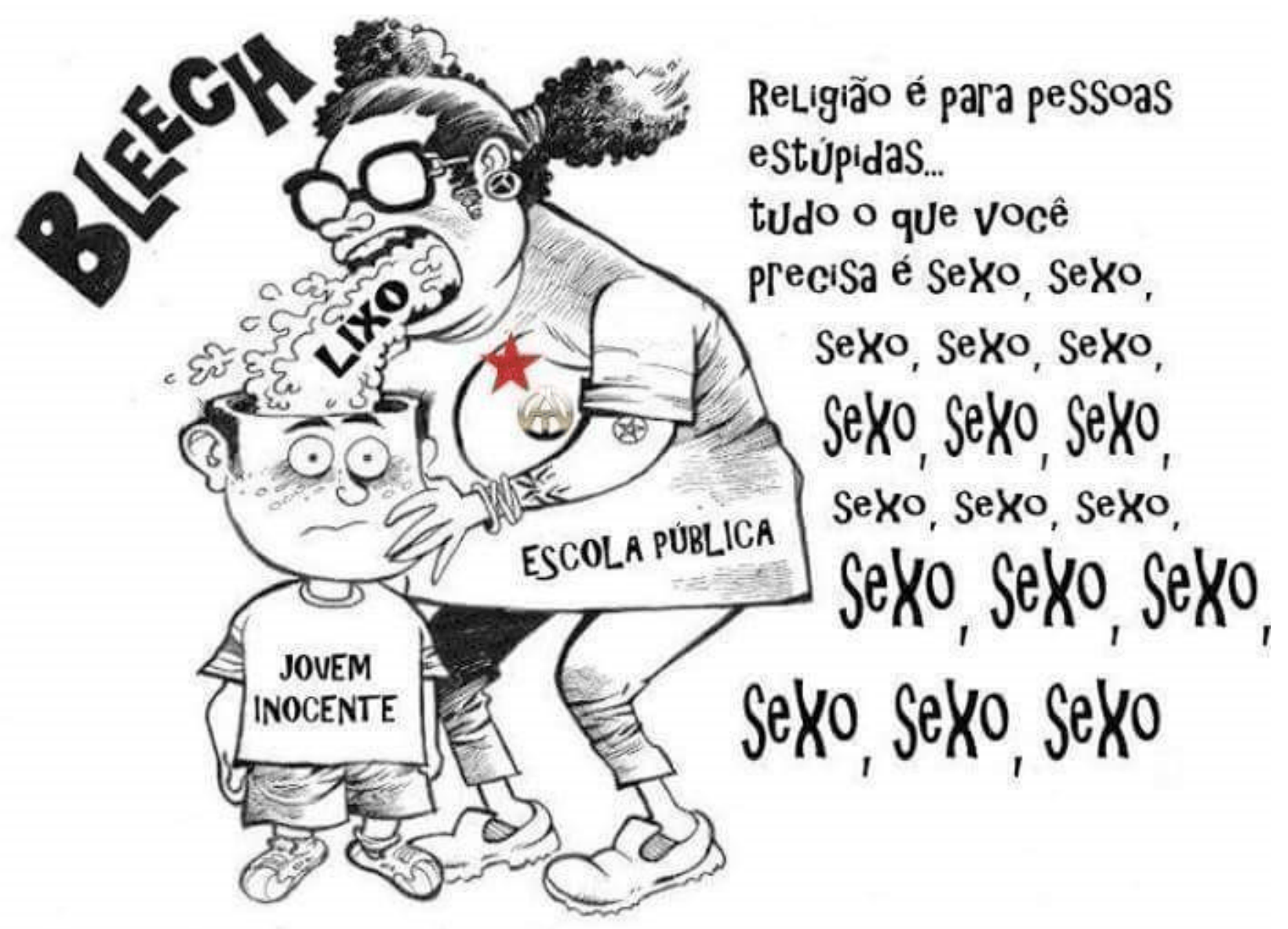

Figura 2. A escola pública e o "jovem inocente"

Fonte: <https://www.facebook.com/escolasempartidooficial/photos/pb.336441753173489.2207520000.1492270099./70 3760683108259/?type=3\&theater $>$

por todo o país, o domínio sobre o discurso de o que é e quais os objetivos do ESP vai saindo do controle de seu "idealizador", Miguel Nagib, fincado mais explícita a vigilância, o controle e a criminalização nos discursos extremistas de deputados conservadores-religiosos. A cada audiência, fica mais perceptível o uso que se quer fazer da educação no Brasil: acabar com qualquer possibilidade de debate e de construção de um pensamento crítico nas escolas - entendido aqui no sentido de fazer pensar sobre uma racionalidade que faz funcionar um modo de governar a todos e que não permite ao povo sair de um estado de dominação e opressão. E, aprofundando a pesquisa, o que se observa é a intenção perversa de controle da população.

Foucault aponta que governar é promover condutas e que, para tanto, deve-se operar no triângulo soberania-disciplina-gestão governamental e ter como alvo a população. De acordo com o autor: "Quando se quiser obter alguma coisa da população - quanto aos comportamentos sexuais, à demografia, ao consumo, etc. - é pela família que se deverá passar. De modelo, a família vai tornar-se instrumento, e instrumento privilegiado, para o governo da população" (1979, p. 289).

É nesse sentido que atua a máxima "meu filho, minhas regras", propagada pelo projeto em discussão. Para conseguir maior adesão da população e justificar a proteção da família, da criança e do adolescente, o projeto inventa categorias como a "ideologia de gênero" que, segundo propaganda partidária veiculada na mídia televisiva, é defendida pelo professor com a intenção de "fazer a cabeça" da criança desde 
a educação infantil, ou como "menino pode ser menina, e menina pode ser menino”. Daí em diante, passa-se a defender que questões morais, religiosas e ideológicas seriam propriedade privada da educação familiar, enquanto ao professor se destinaria a função de apenas instruir. Utilizandose de categorias como neutralidade científica em sobreposição à liberdade de expressão e de pensamento, o que o projeto Escola sem Partido defende é o controle do trabalho de professores e técnicos da educação para que eles atuem apenas na produção de subjetividades normalizadas (Scrivano, Cunha \& Bicalho, 2017).

O ESP acompanha a polarização que se instaurou no país nos últimos anos para em nome da educação manipular um discurso de cuidado com vistas ao controle da população. O movimento favorece determinadas correntes ideológicas e religiosas para dizer à população como deve ser, viver, silenciar e morrer e produzir subjetividades serializadas, úteis ao mercado neoliberal.

Guattari e Rolnik (1986) designam como capitalísticas as sociedades "que vivem numa espécie de dependência e contradependência do capitalismo"(p.15). Nesse sentido, as sociedades que conhecemos como neoliberais podem ser entendidas como as que formariam um capitalismo mundial integrado (CMI), visto que "tais sociedades em nada se diferenciam do ponto de vista do modo de produção de subjetividade"(p.15). Para eles, o CMI se utiliza de procedimentos como a infantilização, a segregação e a culpabilização ${ }^{29}$ para produzir em nós um certo modo serializado de ser e estar no mundo. Esses modos padronizados/serializados marginalizam diversidades e pretendem exterminar ou enquadrar qualquer singularidade que ouse aparecer. E, para dar conta desse controle, passa a ser necessária uma rede de instituições pedagógicas, judiciárias, policiais, psicológicas (Meza\& Bicalho, 2016) e, inclusive, projetos como o Escola sem Partido, que enquadra os indivíduos ao longo de sua existência.
Vale ressaltar que o "público-alvo" do ESP são os educadores, educandos e as famílias das escolas públicas. Isso fica claro quando analisamos o texto do anteprojeto de lei proposto:

Art $3^{\circ} \S 1^{\circ}$ As escolas confessionais e as particulares cujas práticas educativas sejam orientadas por concepções, princípios e valores morais, religiosos ou ideológicos, deverão obter dos pais ou responsáveis pelos estudantes, no ato da matrícula, autorização expressa para a veiculação de conteúdos identificados com os referidos princípios, valores e concepções.

Voltando o olhar para a escola pública, que trabalha com o aluno e famílias pobres, ou seja, com aqueles que o governo neoliberal faz viver até onde interessa e pode "deixar morrer", percebe-se que as racionalidades que constituem o projeto Escola sem Partido teriam por base um racismo de Estado.

Ora, agora o poder é cada vez menos o direito de fazer morrer e cada vez mais o direito de intervir para fazer viver, e na maneira de viver, e no 'como' da vida, a partir do momento em que, portanto, o poder intervém sobretudo nesse nivel para aumentar a vida, para controlar seus acidentes, suas eventualidades, suas deficiências, dai por diante a morte, como termo da vida, é evidentemente o termo, o limite, a extremidade do poder. (Foucault, 2002, p. 295).

E o Estado, na figura de técnicos e cidadãos participativos, utiliza-se de discursos e práticas fascistas:

(...) na medida em que eles determinam
insidiosamente uma padronização
homogeneizada de comportamentos,
sentimentos e falas que invadem e regulam

29 A culpabilização faz com que as pessoas se calem e interiorizem valores e modelos de referência propostos pela sociedade. A infantilização propicia que o Estado pense e organize a vida das pessoas que ele julgue incapazes de decidir e agir por si mesmas. E a segregação mantem a ordem social a partir de sistemas de disciplinarização (Bicalho \&Reishoffer, 2009). 
previamente todos os domínios da vida social cotidiana, abafando a produção de diferenças a partir do mercado econômico como novo lugar de produção da verdade, de desqualificação e de aniquilação. Afinal, o que fazer com aqueles indivíduos e povos que se recusam a assumir-se como empreendedores de si mesmos? (Duarte, 2009, p. 49).

\section{A Escola "sem" Partido e a Formação em Psicologia}

Historicamente, psicólogas e psicólogos são entendidos pelo campo da Educação como os especialistas na correção e/ou no ajustamento de "alunos desviantes" (Cunha \& Bicalho, 2015). É comum vermos professores e técnicos em educação que demandam dos serviços de Psicologia, laudos e psicodiagnósticos que expliquem o porquê de certo aluno "não aprender" ou "não se comportar" como o esperado, serem responsáveis por "tratamentos que curem" comportamentos considerados inadequados. De outro lado, encontramos muitos(as) psicólogos(as) que aceitam esse "lugar", e assim acabam conformando discursos que legitimam desigualdades e as(os) sujeitam a certos modos de ser.

Apostando que a escola, como instituição de transmissão de saber e de produção de subjetividades, pode servir para a transformação ou manutenção de valores que sustentam a sociedade, consideramos de suma importância incluir na formação em Psicologia a discussão sobre o movimento ESP, sua relação de forças e o contexto social, político e econômico que permeiam as políticas subjetivas em tempos de neoliberalismo extremo. Precisamos formar psicólogos que problematizem as relações escolares, e não colaborem com práticas individualizantes, medicalizantes, patologizantes que retiram a autonomia dos educandos e educadores. Do contrário, poderemos ser cooptados pelo ESP e contribuir para a culpabilização dos professores, que nesse caso receberão o rótulo de doutrinadores. Se não ficarmos atentos, alunos e, agora também, professores serão rotulados como fracassados por não possuir méritos, ou como perigosos por habitar o território da "falta" e do "mal", e isso tudo com o aval "científico" da Psicologia.

Que efeitos têm sido produzidos em nosso cotidiano? Que sujeitos, saberes e objetos - os quais não existem em si - estamos o tempo todo produzindo? É preciso colocar em análise nossas práticas, discutindo que profissionais de Psicologia estamos produzindo e que saberes estamos perpetuando.

Propõe-se a recusa da perspectiva que incompatibiliza Psicologia e política, um tipo hegemônico de racionalidade que impõe a oposição dicotômica entre teoria e prática, ciência e ideologia. Habitualmente, intervir como psicólogo pressupõe analisar um território individual, interiorizado, ou no máximo circunscrito a relações interpessoais, transferindo as produções políticas, sociais e econômicas ao campo de estudos de um "outro especialista". "São exteriores à realidade psíquica”, talvez seja esse o argumento (Bicalho, 2005). Tentar percorrer outros caminhos e recusar esse destino, lançando mão de uma “caixa de ferramentas" teórico-conceitual, foi (é) o desafio. Recusar o lugar de "ortopedista social", com seus saberes prontos em planejamentos metodológicos assépticos, mesmo sabendo que inúmeras vezes fomos (somos) capturados pelo enfoque positivista.

É preciso, enfim, pôr em questão nossas implicações: que lugar ocupa-se como especialista? Não é negar o lugar de saber-poder; é assumi-lo, pondo-o o tempo todo em análise, pensando que práticas e lugares são esses que, como psicólogas e psicólogos, somos convidados a ocupar.

E, sobretudo, o que fazemos quando ocupamos o lugar de professores? O que significa atravessar a formação em Psicologia com discussões sobre política e direitos humanos? Que efeitos são produzidos quando colocamos em análise determinados projetos de lei, através de sua proveniência, saberes, diferentes confrontos e produções? Com que ética estamos articulados, e quais subjetividades estamos produzindo? (Meza, Rossotti,\& Bicalho, 2010). 
É preciso adquirir a clareza de que nosso trabalho profissional é também um trabalho político, nunca isento nem neutro. Nossas práticas envolvem uma concepção de mundo, de sociedade, de homem, de humano, exigindo um posicionamento sobre a finalidade da intervenção que fazemos, a qual envolve a certeza de que nossas práticas têm sempre efeitos, exigindo que tomemos, portanto, posições. Nossas escolas sempre terão partido. Resta-nos a pergunta, que jamais deverá deixar de ser feita: a serviço de quem?

\section{Referências}

Araújo, P. M. (2012). O bicameralismo no Brasil: argumentos sobre a importância do Senado na análise do processo decisório federal. Política \& Sociedade, 11(21), 83-135. doi: 10.5007/2175-7984.2012v11n21p83

Bicalho, P.P.G. (2005). Subjetividade e abordagem policial: por uma concepção de direitos humanos onde caibam mais humanos. Tese de doutorado, Universidade Federal do Rio de Janeiro, Rio de Janeiro, RJ, Brasil. Recuperado de: 〈http://goo.gl/zYZ9Yn>

Bicalho, P. P. G.(2016). Da execução à construção das leis: a psicologia jurídica no legislativo brasileiro. In E. P. Brandão(Org.). Atualidades em Psicologia Jurídica. (pp. 17-34). Rio de Janeiro: Nau. Recuperado de <http:// goo.gl/vhhiqB>

Bicalho, P.P.G.,\&Reishoffer, J.C. (2009). Insegurança e produção de subjetividade no Brasil contemporâneo. Fractal: Revista de Psicologia, 21(2), 425-444. Recuperado de <http://goo.gl/DG7dYq>

Bortolini, A. Bicalho, P.P.G. Mostafa, M., Colbert, M., Polato, R.,\& Pinheiro, T. (2014).Trabalhando Diversidade Sexual e de Gênero na Escola: Currículo e Prática Pedagógica. Rio de Janeiro: Instituto de Psicologia-UFRJ. Recuperado de 〈http://goo.gl/eT7YU7>

Cassal, L.C.B., Monteiro, A.G., \& Bicalho, P.P.G. (2011). Psicologia e o dispositivo da sexualidade: biopolítica, identidades e processos de criminalização. Psico, 42, 465-473. Recuperado de 〈http://goo.gl/VvZL93>

Castro, L. A. (2004). Criminologia da Libertação. Rio de Janeiro: Revan.

Cunha, T.C.,\& Bicalho, P.P.G. (2015). Da Palmatória à Polícia: genealogia das lógicas disciplinares no contexto escolar. In: Lemos, F., Galindo, D., Brício, V., Vasco, D., Aguiar, E., \&Almeida, L. (Org.). Psicologia, Educação, Saúde e Sociedade: transversalizando. (pp. 149-162). Curitiba: CRV. Recuperado de <http://goo.gl/zPmmEo >

Duarte, A. (2009). Foucault e as novas figuras da biopolítica: o fascismo contemporâneo In M. Rago, \&A. Veiga-Neto (Orgs.) Para uma vida não fascista.(pp. 35-50). Belo Horizonte: Autêntica Editora.

Foucault, M. (1979). Microfísica do poder. Rio de Janeiro: Edições Graal.
Foucault, M. (2002). Em Defesa da Sociedade. São Paulo: Martins Fontes.

Guattari, F.,\&Rolnik, S.(1986).Micropolítica: cartografias do desejo. Petrópolis: Vozes.

Lemos, L. B. (2008). O Senado Federal brasileiro no pósconstituinte. Brasília: Senado Federal.

Martín-Baró, I. (2017). Crítica e libertação na Psicologia: estudos psicossociais. Organização, notas e tradução de Fernando Lacerda Junior. Petrópolis: Vozes.

Meza, A.P.S., Rossotti, B.G.P., \& Bicalho, P.P.G. (2010). Da ética e da formação: cartografando práticas para além das normas. In: Nórte, C.E., Macieira, R.M., \& Furtado, A.L.L. (Org.). Formação: ética, política e subjetividades na Psicologia. (pp. 178-198). Rio de Janeiro: CRP-05. Recuperado de <http://goo.gl/bWCnjS>

Meza, A.P.S., \& Bicalho, P.P.G. (2016). A Sociedade de Controle que nos Habita. In: Lemos, F.C.S., Galindo, D., Bicalho, P.P.G., Oliveira, F.V., Santos, I.C.,Santos, A., Elmenescay, E.N.M.,\&Almeida, M.T.B. (Org.). Criações Transversais com Gilles Deleuze: Artes, Saberes e Política. (pp. 473-494). Curitiba: CRV. Recuperado de <http:// goo.gl/GZsdKz>

Miskolci,R. (2007). Pânicos morais e controle social reflexões sobre o casamento gay. Cadernos Pagu, (28), 101-128.

Moreira, L., Fulton, T., Uziel, A.P., \& Bicalho, P.P.G. (2010). A Construção da Psicopatia no Contexto da Cultura do Medo. Revista de Psicologia da IMED, 2, 297-306. Recuperado de <http://goo.gl/e1KXuk>

Penna, F. A. (2016). O ódio aos professores. InAção Educativa Assessoria, Pesquisa e Informação (Org.).A ideologia do movimento Escola Sem Partido: 20 autores desmontam o discurso.(pp. 93-100). São Paulo: Ação Educativa.

Scrivano, I, Cunha, F.L.,\& Bicalho, P.P.G.(2017). Escola sem partido: visibilizando racionalidades, analisando governamentalidades. In G. Frigotto (Org.). Escola 'sem' partido: esfinge que ameaça a educação e a sociedade brasileira.(pp. 91-105). Rio de Janeiro: UERJ/ LPP. Recuperado de 〈http://goo.gl/kTz9E9>

Zaffaroni, E. R. (2011). O inimigo no Direito Penal. $3^{\text {a Ed. Rio }}$ de Janeiro: Revan. 